\title{
Vibrio extracellular protease with prothrombin activation and fibrinolytic activities
}

\author{
JU YOUNG KWON ${ }^{1}$, ALAN K. CHANG ${ }^{1}$, JUNG EUN PARK ${ }^{1,4}$, SONG YUB SHIN ${ }^{1}$, \\ SEONG MYEONG YOON ${ }^{2}$ and JUNG SUP LEE LE $^{1,3,4}$
}

\begin{abstract}
${ }^{1}$ Research Center for Proteineous Materials, ${ }^{2}$ Department of Biology, College of Natural Sciences, ${ }^{3}$ Department of Biotechnology, ${ }^{4}$ BK21 Research Team for Protein Activity Control, Chosun University, Gwangju 501-759, Korea
\end{abstract}

Received August 21, 2006; Accepted October 3, 2006

\begin{abstract}
A $36 \mathrm{kDa}$ extracellular metalloprotease (designated to as vEP-MO6) was purified and characterized from Vibrio vulnificus sp. strain MO6 24/0. vEP-MO6 cleaved azocasein and a few other proteins such as prothrombin, plasminogen, fibrinogen and Factor $\mathrm{Xa}$, which are associated with the blood coagulation pathway. The enzyme activity of vEPMO6 was inhibited by EDTA, which was reversed by the addition of excess divalent cations. vEP-MO6 showed little or no activity toward various chromogenic substrates that are specific for other proteases. The cleavage of prothrombin by vEP-MO6 produced active thrombin, as revealed by an activity assay with thrombin-specific chromogenic substrate and Western blot analysis with anti-thrombin antibody. The enzyme also actively hydrolyzed fibrin polymer as well as the cross-linked fibrin. These results suggest that vEP-MO6 is a prothrombin-activating and cross-linked fibrin-degrading enzyme belonging to the metalloprotease family.
\end{abstract}

\section{Introduction}

Various human pathogenic as well as nonpathogenic bacteria secrete metalloproteases (1). Vibrio vulnificus (V. vulnificus) is an opportunistic human pathogen that causes fatal septicemia

Correspondence to: Dr Jung Sup Lee, Department of Biotechnology, College of Natural Sciences, Chosun University, Gwangju 501-759, Korea

E-mail: jsplee@mail.chosun.ac.kr

Abbreviations: BSA, bovine serum albumin; CAPS, 3(cyclohexylamino)-1-propanesulfonic acid; DTT, dithiothreitol; EDTA, ethylenediaminetetraacetic acid; PMSF, phenylmethanesulfonyl fluoride; PVDF, polyvinylidene fluoride; SDS-PAGE, sodium dodecyl sulfate-polyacrylamide gel electrophoresis; TLCK, tosyl-L-lysine-chloromethyl ketone; TPCK, tosyl-L-phenylalanine chloromethyl ketone

Key words: Vibrio vulnificus, metalloprotease, prothrombin activation, fibrinolytic activity characterized by the formation of edematous skin lesions on limbs (2-6). This pathogen secretes a zinc metalloprotease that belongs to the thermolysin family (7-9). The $V$. vulnificus protease has been reported to have many biological functions: proteolytic degradation of a wide variety of host proteins, such as plasma proteins that are involved in coagulation or complement action; induction of hemorrhagic tissue damage; and enhancement of vascular permeability through the generation of inflammatory mediators (7-9).

Fibrinogen and fibrin play essential roles in blood coagulation, cellular and matrix interactions, inflammation, wound healing, and neoplasia (10). During blood coagulation, the soluble fibrinogen is converted to insoluble fibrin, and this process is initiated by thrombin, a serine protease, which catalyzes the proteolytic removal of fibrinopeptides A and B. Fibrinolysis is a physiological process whereby fibrin clots in blood vessels are converted to soluble products. Fibrinolytic enzymes have been purified and characterized from the vampire bat (11), snake venoms (12-14), microorganisms $(15,16)$, hematophagus and non-hematophagus insects (17-20), leeches (21) and earthworms $(22,23)$, marking a new era in the early treatment of heart attack. Their major functions have been described as plasminogen activators or plasmin-like proteases. During fibrinolysis, the fibrin polymer is converted into soluble products by the action of plasmin, which is generated from plasminogen by the proteolytic activity of urokinase-type (uPA) or tissue-type (tPA) plasminogen activators $(24,25)$.

The conversion of prothrombin to thrombin is a key step in the pathway of blood coagulation $(26,27)$. In vivo prothrombin activation is catalyzed by the prothrombinase complex composed of Factor Xa, Factor Va, phospholipids, and calcium ions by the sequential cleavage of two peptide bonds in the prothrombin molecule (28). However, exogenous proteins identified from snake venom $(27,29)$ and bacteria $(30,31)$ have also been found to activate prothrombin in vitro. These proteins are classified into three groups based on their biochemical properties and cofactor requirements for prothrombin activation (32).

Recently we described a broad specificity extracellular metalloprotease protease from $V$. vulnificus sp. strain ATCC 29307 with prothrombin activation and fibrinolytic activities (33). In this study, we extended the investigation to another 36-kDa protease from $V$. vulnificus, sp. strain MO6 24/0. 


\section{Materials and methods}

Materials and chromogenic substrates. Vibrio vulnificus sp. strain MO6 24/0 (V. vulnificus MO6) was a gift from Professor J. H. Lee (Chonnam National University School of Medicine, Gwangju, Korea). HiPrep 16/10 Q FF column, Superdex 75 10/300 GL size exclusion column and PD-10 desalting workmate were purchased from Amersham Biosciences (Uppsala, Sweden). Human prothrombin, thrombin and antithrombin III were from Calbiochem. Human plasminogen, plasmin and Factor Xa were obtained from Roche Applied Science (Indianapolis, MN, USA). Polyvinylidene fluoride (PVDF) membrane was obtained from Bio-Rad (CA, USA). Human fibrinogen and all other chemicals used were from Sigma (USA). The synthetic chromogenic substrate Boc-Val-Pro-Arg- $p$ NA was a kind gift from Professor T. Morita (Meiji Pharmaceutical University, Tokyo, Japan). Other chromogenic substrates obtained from Chromogenix (Milano, Italy) were as follows: lle-Glu-(-OR)Gly-Arg- $p$ NA (S-2222), H-D-Phe-Pip-Arg- $p$ NA (S-2238), H-D-Val-Leu-Lys- $p$ NA (S-2251), H-D-lle-Pro-Arg- $p$ NA (S-2288), Glu-Gly-Arg- $p$ NA (S-2444), MeO-Suc-Arg-ProTyr- $p$ NA (S-2586), and Z-D-Arg-Gly-Arg- $p$ NA (S-2756).

Bacterial cell cultivation and protease purification. $V$. vulnificus MO6 cells were routinely cultured in LB broth with $0.5 \% \mathrm{NaCl}$ as described previously (33). vEP-MO6 was purified from the culture supernatant by employing three purification steps consisting of ammonium sulfate precipitation, anion-exchange chromatography with HiPrep 16/10 Q FF column followed by size-exclusion chromatography with Superdex 75 100/300 GL column as described previously (33). Protein concentrations were determined with Bradford reagent (Sigma) according to the manufacturer's instructions using BSA as a standard.

Protease activity assay. Protease activity was routinely measured with azocasein as a substrate at $37^{\circ} \mathrm{C}$ and $\mathrm{pH} 7.5$ as described previously (33). To study the effect of divalent cations or inhibitors on vEP-MO6 activity, the enzyme was assayed with azocasein in the presence of $1 \mathrm{mM}$ cation or inhibitor. The amidolytic activity of vEP-MO6 was assayed with various synthetic chromogenic substrates, in which $80 \mu 1$ of $50 \mathrm{mM}$ Tris- $\mathrm{HCl}$ buffer (pH 7.5) containing $0.9 \% \mathrm{NaCl}$ and $0.1 \mathrm{mg} / \mathrm{ml} \mathrm{BSA}$ were mixed with $10 \mu 1$ of purified enzyme (typically $1 \mu \mathrm{g}$ ) and the mixture was incubated at $37^{\circ} \mathrm{C}$

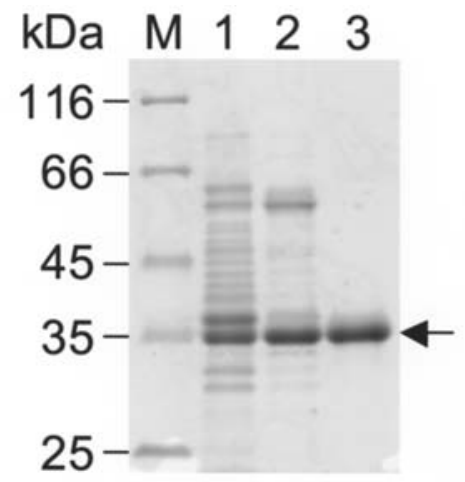

Figure 1. SDS-PAGE of the various purification steps of vEP-MO6. The proteins obtained from each purification step were electrophoresed on $12 \%$ SDS-polyacrylamide gel. Lane $\mathbf{M}$, protein molecular weight markers; 1 , ammonium sulfate precipitate (20-70\%); 2, HiPrep 16/10 Q FF column chromatography; and 3, Superdex 75 10/300 GL size exclusion column chromatography. Arrow indicates the purified enzyme.

for $10 \mathrm{~min}$. The reaction was initiated by adding $10 \mu 1$ of $4 \mathrm{mM}$ chromogenic substrate, and the absorbance at $405 \mathrm{~nm}$ was measured at intervals of $0,5,10,30,60$, and $120 \mathrm{~min}$.

SDS-PAGE and Western blotting. SDS-polyacrylamide gel electrophoresis (SDS-PAGE) was carried out as described by Laemmli (34). Samples were completely denatured in SDSPAGE sample buffer by heating at $100^{\circ} \mathrm{C}$ for 2 min and then electrophoresed in $12 \%$ polyacrylamide gel. Proteins were visualized by staining with Coomassie blue. Western blot analysis was performed as described previously (33).

$N$-terminal sequencing of protease. Protein samples were subjected to electrophoresis on $12 \%$ SDS-polyacrylamide gels. After electrophoresis, proteins were transferred to a PVDF membrane in $10 \mathrm{mM}$ 3-(cyclohexylamino)-1propanesulfonic acid (CAPS) buffer (pH 11.0) containing $10 \%$ methanol. The blot was stained with Coomassie blue followed by destaining. Target bands were excised from the blot and were subjected to $\mathrm{N}$-terminal sequence analysis using an Applied Biosystems Precise sequencer (Applied Biosystems).

Prothrombin activation and fibrinolytic activity. Prothrombin activation by vEP-MO6 and detection of fibrinolytic activity were performed as described previously (33). In brief, $80 \mu \mathrm{g}$

Table I. Purification summary of the protease from Vibrio vulnificus sp. strain MO6 24/0.

\begin{tabular}{lcccr}
\hline Fraction & $\begin{array}{c}\text { Total protein } \\
(\mathrm{mg})\end{array}$ & $\begin{array}{c}\text { Total activity } \\
(\mathrm{U})^{\mathrm{a}}\end{array}$ & $\begin{array}{c}\text { Specific activity } \\
(\mathrm{U} / \mathrm{mg})\end{array}$ & $\begin{array}{r}\text { Yield } \\
(\%)^{\mathrm{b}}\end{array}$ \\
\hline Supernatant & 39.3 & 504,000 & 12,800 & 100 \\
$\left(\mathrm{NH}_{4}\right)_{2} \mathrm{SO}_{4}$ & 12.5 & 168,000 & 13,400 & 33 \\
$\mathrm{HiPrep} \mathrm{Q}$ & 1.2 & 26,000 & 21,700 & 5 \\
Superdex 75 & 0.3 & 9,400 & 31,300 & 2
\end{tabular}

${ }^{\mathrm{a}}$ One unit $(\mathrm{U})$ was defined as the amount of the protease digesting $1 \mu \mathrm{g}$ of azocasein in $1 \mathrm{~min} .{ }^{\mathrm{b}}$ Total activity in the culture supernatant was assigned the value of $100 \%$. 


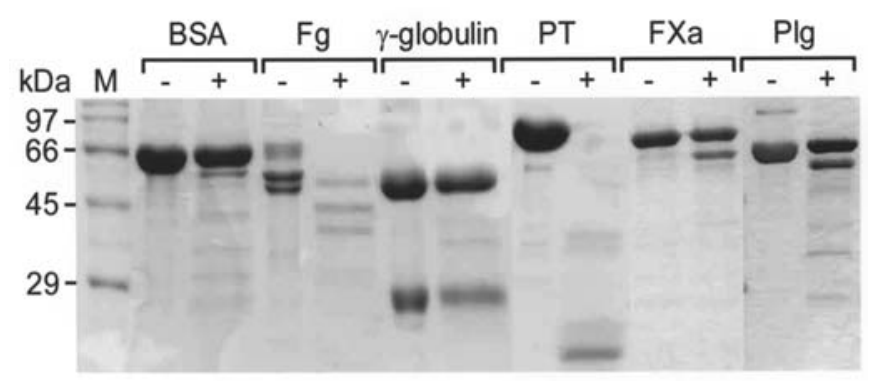

Figure 2. Cleavage of various protein substrates by vEP-MO6 protease. Ten $\mu \mathrm{g}$ of each protein substrate was digested with $0.2 \mu \mathrm{g}$ of vEP-MO6 at room temperature for $20 \mathrm{~min}$ and then subjected to SDS-PAGE using $12 \%$ gel. The symbols + and - indicate the addition or omission of vEP-MO6 in the sample, respectively. M, protein molecular weight size markers; BSA, bovine serum albumin; Fg, fibrinogen; PT, prothrombin; FXa, Factor Xa; and Plg, plasminogen.

of prothrombin and $1 \mu \mathrm{g}$ of vEP-MO6 were incubated in a $200 \mu 1$ reaction volume at room temperature, and $25 \mu 1$ aliquots were withdrawn at different time intervals and the reactions were stopped by the addition of $1 \mu 1$ of $25 \mathrm{mM}$ $\mathrm{NiCl}_{2}$. Thrombin activity was measured with Boc-Val-Pro-Arg$p \mathrm{NA}$ as a substrate. Fibrinolytic activity was measured using a fibrin plate as well as measuring the formation of fibrin polymer detected as an increase in turbidity at $350 \mathrm{~nm}$ as described previously (33). For the detection of vEP-MO6catalyzed cleavage of cross-linked fibrin, the polymerization of fibrin was induced by thrombin in the presence of Factor XIIIa and $\mathrm{Ca}^{2+}$ and then digested with vEP-MO6 followed by SDS-PAGE.

\section{Results}

Purification of extracellular protease. An active extracellular protease designated as vEP-MO6 was purified from the culture supernatant of $V$. vulnificus sp. strain MO6 24/0 cells by using three purification steps consisting of ammonium sulfate precipitation, anion exchange chromatography and size-exclusion chromatography in order as described in Materials and methods. The purification results are summarized in Table I. 21 of culture supernatant, $\sim 0.3 \mathrm{mg}$ of the purified enzyme was obtained with a specific activity of $31,300 \mathrm{U} / \mathrm{mg}$, which was more than three times higher than that of the vEP enzyme from $V$. vulnificus sp. strain ATCC 29307 (33). This represents a 2.45-fold increase over the specific activity of the culture supernatant. The purified enzyme appeared to be homogeneous, as it migrated as a single band with an estimated molecular mass of $\sim 36 \mathrm{kDa}$ (Fig. 1). The purity and size of the enzyme were also confirmed by size-exclusion chromatography with Superdex 75 100/300 GL column (data not shown). These results suggest that the purified enzyme is composed of a single polypeptide. The first 20 amino acids of vEP-MO6 were determined to be AQADGTGPGGNSKTGRYEFG which have a sequence homology ranging from 55-100\% with those of other Vibrio proteases (Table II).

Proteolytic activity of $v E P-M O 6$. For all characterization of the purified enzyme, azocasein was used as a substrate. vEPMO6 had optimum activity around $\mathrm{pH} 8.0$ and a temperature ranging from $30-50^{\circ} \mathrm{C}$. The enzyme activity was reduced to $40 \%$ by heating at $60^{\circ} \mathrm{C}$ for $30 \mathrm{~min}$ (data not shown). Most metalloproteases isolated from different Vibrio species also showed decreased activities at temperatures above $50^{\circ} \mathrm{C}$ (36-38). The $K_{\mathrm{m}}$ for azocasein was determined to be $0.41 \pm 0.03 \mathrm{mg} / \mathrm{ml}$, which is similar to the values obtained for the enzymes from $V$. vulnificus strains ATCC 29307 (33) and L-180 (35). In addition to azocasein, vEP-M06 also cleaved a number of other substrates (Fig. 2), all of which are plasma proteins. Among these, the extent of cleavage was significant for fibrinogen, prothrombin and Factor $\mathrm{Xa}$, all of which are associated with the blood coagulation pathway (Fig. 2). BSA and $\gamma$-globulin, which are not associated with the blood coagulation pathway were only slightly cleaved (BSA) or not cleaved ( $\gamma$-globulin) by vEP-MO6 (Fig. 2). These results suggest that vEP-MO6 has a preference toward blood coagulation-associated proteins, therefore making it a potential risk to the normal homeostasis of blood coagulation. In addition to these protein substrates, the substrate specificity of the enzyme was also examined with various synthetic peptide substrates. Like the vEP enzyme (33), vEP-MO6 also exhibited little or no detectable activity toward the synthetic peptides including S-2222, S-2238, S-2251, S-2288, S-2444, S-2586, and S-2756 after an incubation time of $30 \mathrm{~min}$ at $37^{\circ} \mathrm{C}$.

Table II. Comparison of N-terminal sequence of vEP-MO6 with those of other related proteins.

\begin{tabular}{llrr}
\hline Bacterial strain (protease name) & Amino acid sequence & Position of residues & $\%$ Identity \\
\hline Vibrio vulnificus MO6 24/0 (vEP-MO6) & AQADGTGPGGNSKTGRYEFG & $1-20$ & 100 \\
Vibrio vulnificus ATCC 29307 (vEP) & AQADGTGPGGNSKTGRYEFG & $1-20$ & 100 \\
Vibrio vulnificus YJ016 (zinc metalloprotease) & AQADGTGPGGNSKTGRYEFG & $224-243$ & 100 \\
Vibrio vulnificus CMCP6 (zinc metalloprotease) & AQAGGTGPGGNSKTGRYEFG & $197-216$ & 95 \\
Vibrio proteolyticus (neutral protease precursor) & AQADGTGPGGNTKTGRYEYG & $197-216$ & 90 \\
Vibrio cholerae N16961 (hemagglutinin/protease) & AQATGTGPGGNQKTGRYEYG & $196-215$ & 85 \\
Vibrio harveyi AP6 & AFLEAEGPGGNQKSGRYYFG & $187-197$ \\
& $* \quad \cdot \quad * * * * * * * * * *$ & & 55 \\
\hline
\end{tabular}

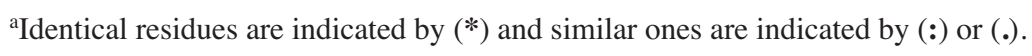


Table III. Effects of protease inhibitors and metal ions on vEP-MO6 activity.

\begin{tabular}{lc}
\hline Additive $^{\mathrm{a}}$ & Activity $(\%)^{\mathrm{b}}$ \\
\hline Control & 100.0 \\
DFP & 99.4 \\
PMSF & 109.2 \\
TLCK & 106.2 \\
TPCK & 75.3 \\
EDTA & 47.0 \\
$1,10-$ phenanthroline & 0.0 \\
Bestatin & 108.8 \\
Aprotinin & 98.8 \\
$\mathrm{DTT}^{2+}$ & 48.2 \\
$\mathrm{Ca}^{2+}$ & 93.7 \\
$\mathrm{Cu}^{2+}$ & 47.6 \\
$\mathrm{Fe}^{2+}$ & 81.1 \\
$\mathrm{Mg}^{2+}$ & 93.7 \\
$\mathrm{Mn}^{2+}$ & 94.5 \\
$\mathrm{Ni}^{2+}$ & 21.7 \\
$\mathrm{Zn}^{2+}$ & 102.8 \\
\hline
\end{tabular}

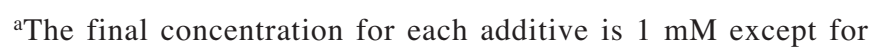
aprotinin, which is $0.5 \mathrm{mM}$. brotease activity was assayed with azocasein as a substrate with or without the corresponding additive at $37^{\circ} \mathrm{C}$ for $15 \mathrm{~min}$.

Table IV. Reversion of EDTA-treated vEP-MO6 enzyme by various divalent cations.

\begin{tabular}{lc}
\hline Additive $^{\mathrm{a}}$ & Relative activity $(\%)^{\mathrm{b}}$ \\
\hline Control & 100.0 \\
EDTA $/ \mathrm{Ca}^{2+}$ & 74.1 \\
EDTA $/ \mathrm{Cu}^{2+}$ & 17.2 \\
EDTA $/ \mathrm{Mg}^{2+}$ & 41.8 \\
EDTA $/ \mathrm{Mn}^{2+}$ & 169.0 \\
EDTA $/ \mathrm{Ni}^{2+}$ & 18.0 \\
EDTA $/ \mathrm{Zn}^{2+}$ & 24.3 \\
EDTA & 30.1 \\
\hline
\end{tabular}

${ }^{\mathrm{a}}$ vEP-MO6 was pre-incubated with $1 \mathrm{mM}$ EDTA at $37^{\circ} \mathrm{C}$ for $15 \mathrm{~min}$ followed by the addition of excess cation $(5 \mathrm{mM})$ and a further 15 -min incubation. ${ }^{b}$ Relative protease activity was assayed with $0.25 \%$ azocasein as substrate at $37^{\circ} \mathrm{C}$ for $20 \mathrm{~min}$.

Effects of various protease inhibitors, metal ions and chelating agents. Inhibition studies primarily give insight into the nature of an enzyme, its cofactor requirements, and the nature of the active center (39). To confirm that vEP-MO6 belongs to the metalloprotease family, the enzyme activity was assayed in the presence of metal chelators such as EDTA and 1,10-phenanthroline or various protease inhibitors. As shown in Table III, the enzyme activity was only
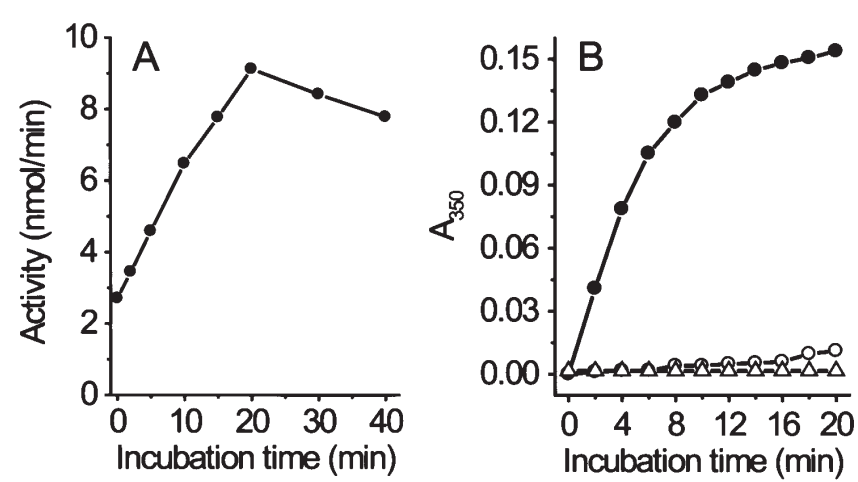

Figure 3. Activation of prothrombin by vEP-MO6. (A) Thrombin activity was measured with thrombin-specific chromogenic substrate Boc-Val-ProArg- $p$ NA. Prothrombin $(0.4 \mathrm{mg} / \mathrm{ml})$ was activated by vEP-MO6 $(0.8 \mu \mathrm{g} / \mathrm{ml})$ at room temperature, aliquots were withdrawn at different time intervals and the reaction was stopped by the addition of $1 \mathrm{mM} \mathrm{NiCl}_{2}$. (B) Thrombin activity was assayed by measuring the degree of fibrin formation. Prothrombin activated by vEP-MO6 for 20 min was mixed with fibrinogen $(0.5 \mathrm{mg} / \mathrm{ml})$ in the presence of $1 \mathrm{mM} \mathrm{NiCl}_{2}$, and the formation of fibrin polymer was monitored as an increase in turbidity at $350 \mathrm{~nm}$. •, Prothrombin plus vEPMO6;, prothrombin only; and $\triangle$, vEP-MO6 only.

significantly inhibited by EDTA and 1,10-phenanthroline with the latter resulting in total inhibition. Other protease inhibitors that inhibit serine or cysteine proteases appeared to have no significant effect. vEP-MO6 is therefore a metalloprotease, like extracellular proteases from other $V$. vulnificus strains or Vibrio species. To note, DTT also caused significant inhibition of vEP-MO6 activity, suggesting that the presence of disulfide bonds within the protein may be necessary for maintaining full enzyme activity. The effect of divalent metal ions on vEP-MO6 activity was also studied. Inclusion of $1 \mathrm{mM}$ $\mathrm{Ca}^{2+}, \mathrm{Mg}^{2+}$ or $\mathrm{Mn}^{2+}$ appeared to have no significant effects, whereas inclusion of $1 \mathrm{mM} \mathrm{Cu}^{2+}$ or $\mathrm{Ni}^{2+}$ was highly inhibitory (Table III). To ascertain which metal ion could reverse the inhibitory effect of EDTA-inactivated vEP-MO6, the enzyme was first pre-incubated with $1 \mathrm{mM}$ EDTA for $15 \mathrm{~min}$ at $37^{\circ} \mathrm{C}$, followed by incubation with excess metal ions $(5 \mathrm{mM})$ for another $15 \mathrm{~min}$ before addition of azocasein and a further incubation of $20 \mathrm{~min}$ at the same temperature. $\mathrm{Ca}^{2+}, \mathrm{Mg}^{2+}$ and $\mathrm{Mn}^{2+}$ were observed to reverse the inhibitory effect of EDTA (Table IV). $\mathrm{Cu}^{2+}$ and $\mathrm{Ni}^{2+}$, which are inhibitory to the activity of vEP-MO6 failed to reverse the activity of the enzyme. The lack of reversion of enzyme activity by $\mathrm{Zn}^{2+}$ was due to excess concentration of the metal ion, which becomes inhibitory for a $\mathrm{Zn}$-dependent protease (40).

Prothrombin activation by $v E P-M O 6$. Prothrombin was a very efficient substrate for vEP-MO6 with almost complete cleavage occurring at room temperature within $20 \mathrm{~min}$ of incubation (Fig. 3). To detect thrombin activity, prothrombin was cleaved with lesser amount of vEP-MO6, and aliquots of the reaction mixture were taken at different time intervals for activity assay with thrombin-specific chromogenic substrate, Boc-Val-Pro-Arg- $p$ NA. The activity toward Boc-Val-Pro-Arg$p \mathrm{NA}$ increased with time with maximum activity obtained at $20 \mathrm{~min}$, and then started to drop beyond that time point (Fig. 3A). To test whether the product of prothrombin- 
A

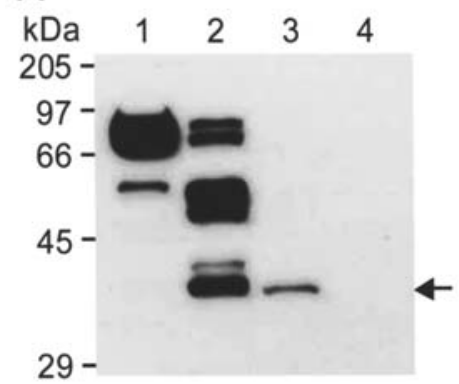

B

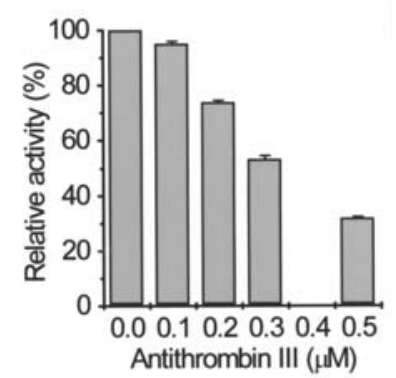

Figure 4. Production of thrombin from prothrombin by vEP-MO6. (A) Western blot analysis of vEP-MO6-activated prothrombin. vEP-MO6treated prothrombin was subjected to SDS-PAGE, and the proteins were transferred to PVDF membrane. The blot was probed with antibody raised against thrombin. Lane 1, prothrombin; 2, vEP-MO6-activated prothrombin; 3 , thrombin; and 4, vEP-MO6. (B) Effect of antithrombin III on the activity of vEP-MO6-activated prothrombin. Prothrombin $(0.4 \mathrm{mg} / \mathrm{ml})$ was activated by vEP-MO6 $(0.8 \mu \mathrm{g} / \mathrm{ml})$ at room temperature for $20 \mathrm{~min}$, and the reaction was terminated by the addition of $1 \mathrm{mM} \mathrm{NiCl}_{2}$. Aliquots were assayed with Boc-VPR-pNA $(0.4 \mathrm{mM})$ as a substrate in the presence or absence of antithrombin III.

A

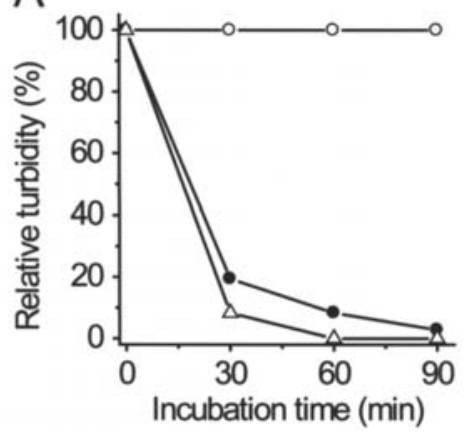

B

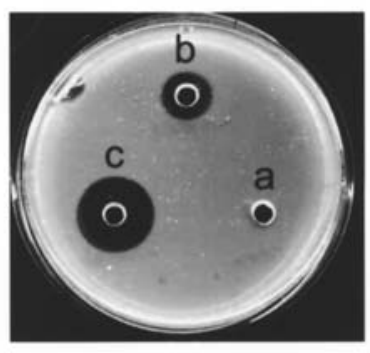

Figure 5. Fibrinolytic activity of vEP-MO6. (A) Measurement of the change in turbidity of fibrin polymer. Assay was performed as described in Materials and methods. Cleavage of fibrin polymer was expressed as a percentage of the decrease in turbidity relative to that at zero time. $\bullet$ Tris- $\mathrm{HCl}$ buffer ( $\mathrm{pH} 7.5$ ); •, vEP-MO6; and $\triangle$, plasmin. (B) Analysis of fibrinolytic activity on fibrin-agarose plate. Samples were added into the hole in the plate and incubated at $37^{\circ} \mathrm{C}$ for $12 \mathrm{~h}$. a, Tris- $\mathrm{HCl}$ buffer ( $\mathrm{pH} \mathrm{7.5);} \mathrm{b,} \mathrm{vEP-}$ MO6 $(2 \mu \mathrm{g})$; and c, plasmin $(1.2 \mu \mathrm{g})$.

activation by vEP-MO6 also catalyzes the formation of fibrin polymer, the vEP-MO6-activated prothrombin was reacted with fibrinogen and the increase in turbidity was measured at $350 \mathrm{~nm}$ (Fig. 3). There was a clear increase in turbidity only when fibrinogen was incubated with vEP-MO6-activated prothrombin (Fig. 3B). Production of a functional thrombin from prothrombin by vEP-MO6 was further confirmed by Western blot analysis and an inhibitor study using antithrombin III. Western blot analysis with antibody raised against thrombin detected various major bands that were not seen with uncleaved prothrombin (Fig. 4A). One of these bands corresponded to the band of thrombin control, indicated by an arrow in Fig. 4A. In addition, the activity of vEP-MO6-activated prothrombin was clearly inhibited by antithrombin III in a dose-dependent manner (Fig. 4B). The activation of prothrombin by vEP-MO6 was $\mathrm{Ca}^{2+}$-independent, as in the case of other bacterial proteases that are capable of activating prothrombin.
Fibrinolytic activity of $v E P-M O 6$. vEP-MO6 cleaved all three chains of fibrinogen, unlike most other proteases that are known to cleave fibrinogen, including the enzyme from a related Vibrio strain L-180 (35) that cleaved either one of two fibrinogen chains but not all three. The fibrinolytic activity of vEP-MO6 protease was confirmed by its ability to degrade fibrin polymer, which was measured as a decrease in turbidity of the polymer at $350 \mathrm{~nm}$ (Fig. 5A) as well as the formation of a cleared zone on a fibrin plate (Fig. 5B). The results from the fibrin plate showed that vEP-M06 is a less efficient enzyme than plasmin in degrading fibrin. However, vEPMO6 also cleaved the cross-linked fibrins formed by Factor XIIIa in the presence of $\mathrm{Ca}^{2+}$ (Fig. 6). Both the $\alpha-\alpha$ and $\gamma-\gamma$ chains of the fibrins were susceptible to cleavage by vEPMO6.

\section{Discussion}

This study describes the purification and characterization of an active extracellular metalloprotease named vEP-MO6 from $V$. vulnificus sp. strain MO6 24/0. The following results support the fact that vEP-MO6 is a metalloprotease: i) serine or cysteine protease inhibitors including DFP, PMSF, TLCK, TPCK, bestatin, and aprotinin have no significant effect on the enzyme activity; ii) metal chelators such as EDTA and EGTA (data not shown) inactivate the enzyme activity; and iii) metalloprotease-specific inhibitors such as 1,10 phenanthroline totally inactivate the enzyme activity.

In general, vEP-MO6 exhibits broad specificity toward various protein substrates. However, it has a preference toward cleaving blood coagulation-associated proteins (Fig. 2), therefore making it a potential risk factor to the normal homeostasis of blood coagulation. The broad specificity of vEP-MO6 toward protein substrates is clearly not reflected in its activity toward peptide substrates in that the enzyme shows little or no detectable activity with various tested synthetic peptides, which are specific chromogenic substrates for other proteases. For example, vEP-MO6 can activate prothrombin but does not cleave S-2222, both of which are substrates for factor Xa. Plasminogen and S-2444 are substrates for urokinase, but vEP exhibits little activity toward S-2444, although it can readily cleave plasminogen. Although we did not obtain the cleavage site for the proteins that were readily cleaved by vEP-MO6, the cleavage sites for prothrombin and plasminogen recognized by vEP-MO6 appear to bear little consensus. Therefore the surrounding sequence and/or the conformation of the local region of a protein may be important factors for the binding of vEPMO6 to the substrate and subsequent cleavage.

One of the notable properties of vEP-MO6 protease is its possible involvement in the blood coagulation cascade. vEPMO6 activates prothrombin to produce an active thrombin in the course of proteolysis (Fig. 3), leading to the cleavage of fibrinogen followed by formation of fibrin polymer (Fig. 3B), including cross-linked fibrins formed in the presence of FXIII and $\mathrm{Ca}^{2+}$. Evidence that a functional thrombin is produced from prothrombin catalyzed by vEP-MO6 is seen from the activity assay with thrombin-specific chromogenic substrate (Fig. 3A), the turbidity assay with fibrinogen (Fig. 3B), the Western blotting with anti-thrombin antibody (Fig. 4A) and 


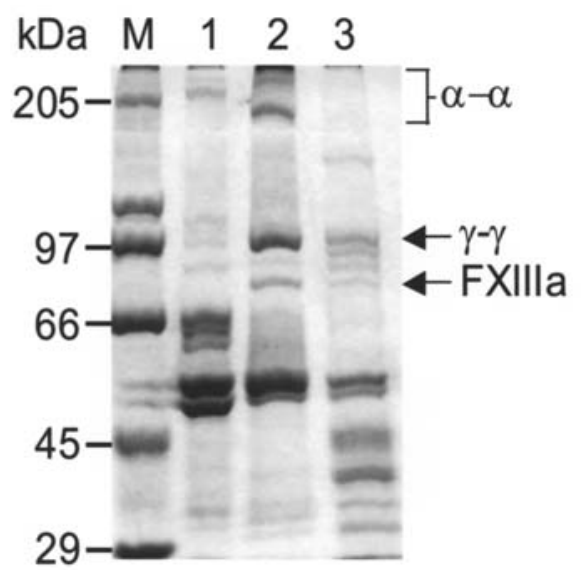

Figure 6. SDS-PAGE of the cleavage of $\alpha$ - and $\beta$-chain cross-links of fibrin by vEP-MO6. Polymerization of fibrinogen $(0.75 \mathrm{mg} / \mathrm{ml})$ was initiated with the addition of thrombin $(1.5 \mathrm{U} / \mathrm{ml})$, Factor XIIIa $(0.15 \mathrm{U} / \mathrm{ml})$ and $1 \mathrm{mM}$ $\mathrm{CaCl}_{2}$ followed by incubation at room temperature for $1 \mathrm{~h}$. The cross-linked fibrin was digested with vEP-MO6 $(10 \mu \mathrm{g} / \mathrm{ml})$ at room temperature for $30 \mathrm{~min}$ followed by SDS-PAGE using $8 \%$ gel. Lane M, protein size markers; 1 , fibrinogen only; 2, thrombin plus FXIIIa; and 3, thrombin, FXIIIa plus vEPMO6.

conclusively from the inhibition of thrombin activity from prothrombin activation by vEP-MO6 with antithrombin III (Fig. 4B). The activated prothrombin by vEP-MO6 shows strong amidolytic activity toward the thrombin-specific peptide substrate Boc-Val-Pro-Arg-pNA (Fig. 3A) like $\alpha$-thrombin (29) and also increases the turbidity of fibrinogen solution, which is the result of the formation of fibrin polymer, in which the fibrin is produced from fibrinogen cleavage by thrombin activated from prothrombin by vEP-MO6 (Fig. 3B). Western blotting with anti-thrombin antibody reconfirms that thrombin is actually produced from prothrombin cleavage by vEP-MO6. As shown on the Western blot (Fig. 4A), vEP-MO6 cleaves prothrombin to make several fragments including thrombin. However, the presence of the thrombin band disappeared after a longer incubation, together with other protein bands. This seems to be closely related to the broad specificity of vEP-MO6 and also explains that the decrease in thrombin activity with time may be due to further degradation of thrombin by the enzyme after its generation from prothrombin. Therefore, the activation of prothrombin by vEP is proteolysisdependent and transient. In contrast, certain microbial prothrombin-activating enzymes such as staphylocoagulase from Staphylococcus aureus are involved in blood coagulation by conformational activation of prothrombin without proteolysis and loss of thrombin activity (41). Another notable property of vEP-MO6 in the activation of prothrombin is its $\mathrm{Ca}^{2+}$-independent manner like vEP protease (33) and a metalloprotease from Aeromonas hydrophila (42), whereas the prothrombin activation by endogenous human FXa and carinactivase protease from snake venom (29) required $\mathrm{Ca}^{2+}$.

Fibrinolytic enzymes have been purified and characterized from many sources $(15-17,21,23)$. The fibrinolytic activity of vEP-MO6 (Fig. 5) is different from those reported for other fibrinolytic enzymes because it is capable of digesting all three major chains $(\alpha, \beta$, and $\gamma)$ of fibrinogen as well as $\alpha-\alpha$ and $\gamma-\gamma$ fibrin chains of cross-linked fibrin (Fig. 6). The same protease from $V$. vulnificus L-180 only cleaved the A $\alpha$-chain of fibrinogen (35). Both the $\mathrm{A} \alpha$ - and $\mathrm{B} \beta$-chains are cleaved by plasmin, whereas the $\gamma$-chain is resistant to both proteases. Certain fibrinolytic enzymes isolated from other sources also exhibit some degree of specificity with respect to the cleavage of fibrinogen as shown in the case of shrimp protease which cleaved the $\beta$ - or the $\gamma$-chain only (43).

In conclusion, vEP-MO6 is a protease that has very similar properties to the vEP protease from $V$. vulnificus sp. strain ATCC 29307 in terms of substrate specificity, prothrombin activation and fibrinolytic activity. The possible interference of this enzyme in the blood coagulation pathway is manifested through the enzyme's ability to activate prothrombin and cleave fibrinogen and fibrin. We have previously postulated a possible role for this protease during infection, whereby the prothrombin activation activity could lead to a rapid build-up of fibrin mess that can serve to protect the bacteria from the host defense machinery, with subsequent release of an increasing number of bacteria from the fibrin mess attained through the enzyme's ability to cleave fibrin and fibrinogen (33). Due to the very similar properties between vEP-MO6 and vEP proteases, such a postulation would apply to both strains of $V$. vulnificus.

\section{Acknowledgements}

This work was supported by the ERC program of MOST/ KOSEF through the Research Center for Proteineous Materials (RCPM) of Chosun University, and by research funds from Chosun University, 2003. Alan K. Chang was supported by the Korea Research Foundation Grant no. 410006.

\section{References}

1. Hase CC and Finkelstein RA: Bacterial extracellular zinccontaining metalloproteases. Microbiol Rev 57: 823-837, 1993.

2. Janda JM, Powers C, Bryant RG and Abbott SL: Bacterial extracellular zinc-containing metalloproteases. Clin Microbiol Rev 1: 245-267, 1988.

3. Park SD, Shon HS and Joh NJ: Vibrio vulnificus septicemia in Korea: clinical and epidemiologic findings in seventy patients. $\mathrm{J}$ Am Acad Dermatol 24: 397-403, 1991.

4. Chiang SR and Chuang YC: Vibrio vulnificus infection: clinical manifestations, pathogenesis and antimicrobial therapy. J Microbiol Immunol Infect 36: 81-88, 2003.

5. Tacket CO, Brenner F and Blake PA: Clinical features and an epidemiological study of Vibrio vulnificus infections. J Infect Dis 149: 558-561, 1984.

6. Ulusarac $\mathrm{O}$ and Carter E: Varied clinical presentations of Vibrio vulnificus infections: a report of four unusual cases and review of the literature. South Med J 97: 163-168, 2004

7. Miyoshi S and Shinoda S: Microbial metalloproteases and pathogenesis. Microbes Infect 2: 91-98, 2000.

8. Miyoshi S, Oh EG, Hirata K and Shinoda S: Exocellular toxic factors produced by Vibrio vulnificus. J Toxicol Toxin Rev 12: 253-288, 1993.

9. Miyoshi S, Kawata K, Hosokawa M, Tomochika K and Shinoda S: Histamine-releasing reaction induced by the $\mathrm{N}$-terminal domain of Vibrio vulnificus metalloprotease. Life Sci 72: 2235-2242, 2003.

10. Mosesson MW: Fibrin polymerization and its regulatory role in hemostasis. J Lab Clin Med 116: 8-17, 1990.

11. Cartwright T: The plasminogen activator of vampire bat saliva. Blood 43: 317-326, 1974

12. Bajwa SS, Kirakossian H, Reddy KN and Markland FS: Thrombin-like and fibrinolytic enzymes in the venoms from the Gaboon viper (Bitis gabonica), eastern cottonmouth moccasin (Agkistrodon p. piscivorus) and southern copperhead (Agkistrodon c. contortrix) snakes. Toxicon 20: 427-432, 1982. 
13. Siigur E and Siigur J: Purification and characterization of lebetase, a fibrinolytic enzyme from Vipera lebetina (snake) venom. Biochim Biophys Acta 1074: 223-229, 1991.

14. Zhang Y, Wisner A, Xiong Y and Bon C: A novel plasminogen activator from snake venom. Purification, characterization, and molecular cloning. J Biol Chem 270: 10246-10255, 1995.

15. Fujita M, Nomura K, Hong K, Ito Y, Asada A and Nishimuro S: Purification and characterization of a strong fibrinolytic enzyme (nattokinase) in the vegetable cheese natto, a popular soybean fermented food in Japan. Biochem Biophys Res Commun 197: 1340-1347, 1993.

16. Kim W, Choi K, Kim Y, Park H, Choi J, Lee Y, Oh H, Kwon I and Lee S: Purification and characterization of a fibrinolytic enzyme produced from Bacillus sp. strain CK 11-4 screened from Chungkook-Jang. Appl Environ Microbiol 62: 2482-2488, 1996.

17. Hellmann K and Hawkins RI: Anticoagulant and fibrinolytic activities from Rhodnius prolixus stal. Nature 201: 1008-1009, 1964.

18. Ben Hamouda MH and Ammar M: Identification of plasminogen activators in the saliva of Rhapactor biparticeps (Reduviidae). Arch Inst Pasteur Tunis 61: 165-170, 1984.

19. Amarant T, Burkhart W, LeVine H III, Arocha-Pinango CL and Parikh I: Isolation and complete amino acid sequence of two fibrinolytic proteinases from the toxic Saturnid caterpillar Lonomia achelous. Biochim Biophys Acta 1079: 214-221, 1991.

20. Matsushima A, Shioya K, Kobayashi M, Kodera Y and Inada Y: Activation of fibrinolysis with the protease from Dermatophagoides farinae. Thromb Haemost 70: 545, 1993.

21. Chudzinski-Tavassi AM, Kelen EM, de Paula Rosa AP, Loyau S, Sampaio CA, Bon C and Angles-Cano E: Fibrino(geno)lytic properties of purified hementerin, a metalloproteinase from the leech Haementeria depressa. Thromb Haemost 80: 155-160, 1998.

22. Nakajima N, Mihara H and Sumi H: Characterization of potent fibrinolytic enzymes in earthworm, Lumbricus rubellus. Biosci Biotechnol Biochem 57: 1726-1730, 1993.

23. Hrzenjak T, Popovic M, Bozic T, Grdisa M, Kobrehel D and Tiska-Rudman L: Fibrinolytic and anticoagulative activities from the earthworm Eisenia foetida. Comp Biochem Physiol B Biochem Mol Biol 119: 825-832, 1998.

24. Collen D and Lijnen HR: Molecular basis of fibrinolysis, as relevant for thrombolytic therapy. Thromb Haemost 74: 167-171, 1995.

25. Murphy G, Willenbrock F, Crabbe T, O'Shea M, Ward R, Atkinson S, O'Connell J and Docherty A: Regulation of matrix metalloproteinase activity. Ann NY Acad Sci 732: 31-41, 1994.

26. Davie EW and Ratnoff OD: Waterfall sequence for intrinsic blood clotting. Science 145: 1310-1312, 1964.

27. Gao R, Manjunatha Kini R and Gopalakrishnakone P: A novel prothrombin activator from the venom of Micropechis ikaheka: isolation and characterization. Arch Biochem Biophys 408: 87-92, 2002.
28. Maan KG: Prothrombin and thrombin. In: Hemostasis and Thrombosis: Basic Principles and Clinical Practice. Colman RW, Hirsh J, Marder VJ, Salman EW, Salzman JB and Lippincott JB (eds). Lippincott, Philadelphia, pp184-199, 1994.

29. Yamada D, Sekiya F and Morita T: Isolation and characterization of carinactivase, a novel prothrombin activator in Echis carinatus venom with a unique catalytic mechanism. J Biol Chem 271: 5200-5207, 1996.

30. Wegrzynowicz Z, Heczko PB, Drapeau GR, Jeljaszewicz J and Pulverer G: Prothrombin activation by a metalloprotease from Staphylococcus aureus. J Clin Microbiol 12: 138-139, 1980.

31. Kaminishi H, Hamatake H, Cho T, Tamaki T, Suenaga N, Fujii T, Hagihara $\mathrm{Y}$ and Maeda H: Activation of blood clotting factors by microbial proteinases. FEMS Microbiol Lett 121: 327-332, 1994.

32. Rosing $\mathrm{J}$ and Tans G: Structural and functional properties of snake venom prothrombin activators. Toxicon 30: 1515-1527, 1992.

33. Chang AK, Kim HY, Park JE, Acharya P, Park IS, Yoon SM, You HJ, Hahm KS, Park JK and Lee JS: Vibrio vulnificus secretes a broad-specificity metalloprotease capable of interfering with blood homeostasis through prothrombin activation and fibrinolysis. J Bacteriol 187: 6909-6916, 2005.

34. Laemmli UK: Cleavage of structural proteins during the assembly of the head of bacteriophage T4. Nature 227: 680-685, 1970.

35. Miyoshi N, Shimizu C, Miyoshi S and Shinoda S: Purification and characterization of Vibrio vulnificus protease. Microbiol Immunol 31: 13-25, 1987.

36. Farto R, Perez MJ, Fernandez-Briera A and Nieto TP: Purification and partial characterization of a fish lethal extracellular protease from Vibrio pelagius. Vet Microbiol 89: 181-194, 2002.

37. Teo JW, Zhang LH and Poh CL: Cloning and characterization of a metalloprotease from Vibrio harveyi strain AP6. Gene 303: 147-156, 2003.

38. Lee JH, Ahn SH, Lee EM, Kim YO, Lee SJ and Kong IS: Characterization of the enzyme activity of an extracellular metalloprotease (VMC) from Vibrio mimicus and its C-terminal deletions. FEMS Microbiol Lett 223: 293-300, 2003.

39. Sigman DS and Mooser G: Chemical studies of enzyme active sites. Annu Rev Biochem 44: 899-931, 1975.

40. Holland DR, Hausrath AC, Juers D and Matthews BW: Structural analysis of zinc substitutions in the active site of thermolysin. Protein Sci 4: 1955-1965, 1995.

41. Panizzi P, Friedrich R, Fuentes-Prior P, Bode W and Bock PE: The staphylocoagulase family of zymogen activator and adhesion proteins. Cell Mol Life Sci 61: 2793-2798, 2004.

42. Keller T, Seitz R, Dodt J and Konig H: A secreted metalloprotease from Aeromonas hydrophila exhibits prothrombin activator activity. Blood Coagul Fibrinolysis 15: 169-178, 2004.

43. Wong AH and Mine Y: Novel fibrinolytic enzyme in fermented shrimp paste, a traditional Asian fermented seasoning. J Agric Food Chem 52: 980-986, 2004. 